IOSR Journal of Pharmacy

ISSN: 2250-3013, www.iosrphr.org

||| Volume 2 Issue 5 ||| Sep-Oct. 2012 || || PP.01-04

\title{
Cervical cytology in women with abnormal cervix.
}

\author{
Dr. Veena Rahatgaonkar ${ }^{1}$, Dr. Savita Mehendale ${ }^{2}$ \\ ${ }^{1}$ Associate Professor \& In charge of Cancer Detection Center, Dept. of Gynecology, Bharati \\ Vidyapeeth Medical College, Sangli (India). \\ ${ }^{2}$ Professor, Dept. of Gynecology, Bharati Vidyapeeth Medical College, Pune (India).
}

\begin{abstract}
Objectives: - To study cervical cytology in women with abnormal cervical findings on visual inspection. Methods:- Descriptive analytical study was conducted in Department of Gynecology \& Obstetrics, Bharati Vidyapeeth Medical College, Pune, India.1600 women from Gynecology OPD having abnormal cervical findings on visual inspection were included in study. These women were subjected for Pap smear.

Results: - Inflammatory changes were seen in $47.75 \%$ and precancerous lesions seen in $9.56 \%$ patients. Out of which LSIL was seen in $6.75 \%$ and HSIL was (CIN II \& CIN III) in $2.81 \%$ of patients. In present study mean age for CIN was $38.13 \pm 9.03$ years. Malignant lesions were detected in $0.56 \%$ of patients, maximum in age group 41-45 years.

Conclusion: - Women with abnormal cervical findings on visual inspection should be subjected to Pap smear to detect the disease in precancerous stage \& to lower the mortality \& morbidity.
\end{abstract}

Keywords-Cancer, HSIL, LSIL, Pap smear

\section{INTRODUCTION}

Worldwide cervical cancer is the second most common cancer in females, comprising of $12 \%$ of all cancers in women.[1] In 2004, 4,89,000 new cases and 2,68,000 deaths from cervical cancer were noted worldwide. Global burden of cervical cancer is greatest in developing countries, contributing $85 \%$ of new cases $\& 83 \%$ of cervical cancer deaths. [1,2] In India it is an important public health problem for women, leading to annual mortality of 70,000. [2]

Effective screening will contribute to lower mortality \& morbidity associated with frank malignancy of cervix.[3] Cytological methods of screening for cervical cancer \& precancer have become the mainstay of population based prevention programs, resulting in substantial reduction of the disease in countries such as Canada \& Finland where mass screening is done.[ 4]Existing screening programs of Mass screening by Pap smear are failing to achieve major impact with respect to progression of disease in low resource countries like India due to paucity of human \& financial resources .[5]

So there is need for alternate strategy to concentrate on women with high risk. Hence we selected target population with abnormal cervical finding for Pap smear test for the study.

\section{MATERIALS AND METHODS}

The present prospective study started after ethical committee clearance. This descriptive study was conducted in Department of Gynecology, Bharati Vidyapeeth Medical College, Pune during Jan 2004 to Jan 2009. Total 1600 women from Gynecology OPD with abnormal cervical finding on visual inspection like cervical erosion, cervicitis, hypertrophied cervix and cervix bleeding on touch were included after taking informed consent. After detailed history, per speculum examination was done. PAP smear was taken with Ayres's spatula from ecto-cervix and with cytobrush from endo-cervix. After fixing smears with cyotofix spray, slides were stained with PAP stain. Interpretation and reporting was done by cytologist as per nomenclature of The Bethesda classification 2001.[6]

\section{RESULTS AND ANALYSIS}

In present study on visual inspection of cervix, following findings were noted;Cervicitis - 782 women,Cervical erosion - 619 Hypertrophied cervix - 84 Cervix bleeding on touch - 115

Women with hypertrophied cervix and cervix bleeding on touch had higher percentage of cases of cancer. $(3.57 \% \& 3.48 \%$ respectively). 


\section{Table A1}

Table A2

In $502(31.38 \%)$ women no cytological abnormality was seen. CIN was detected in $153(9.56 \%)$ and cervical cancer in $9(0.56 \%)$ women.

Out of total CIN patients, Low grade squamous intraepithelial lesion (LSIL) in $108(6.75 \%)$ \& High grade squalors intraepithelial lesion (HSIL) was seen in 45 (2.81\%) patients. (Fig.1)

Women's mean age in the study was $32.7 \pm 10.04$ years. Mean age of CIN was $38.13 \pm 9.03$ years.

Mean age of LSIL was $37.53 \pm 9.16$ years

Mean age of HSIL was $39.5 \pm 8.55$ years

Mean age of cervical malignancy was $45.77 \pm 8.53$ years.

No statistical difference between mean ages of patients detected to have LSIL \& HSIL was seen by Z test (S.E. difference between mean ages) $\mathrm{z}$ value $1.236 \& \mathrm{p}$ value $>0.05$

Out of positive screeners for malignancy, 1 adenocarcinoma and 8 squamous cell carcinoma were detected.

\section{DISCUSSION}

Cervical cancer is preceded by spectrum of cytomorphological changes called as cervical intraepithelial neoplasia (CIN) for many years before development of frank malignancy.[7,8] Detection \& treatment of disease at this stage halts the progression of disease. PAP smear is non-invasive, easy technique where sample of cervical cells is taken by health provider \& examined by trained cytologist. [9 ]This test has history of long use since 1950 in many developed countries.

Both incidence \& mortality from cervical cancer have sharply decreased in a number of large populations following the introduction of well run screening programs.[10,11] Pap smear test has excellent specificity (95\%) while sensitivity is moderate (44 - 78\%). [12] Adequate training in sample collection, use of cytobrush for taking smear, newer technique like Thin Prep or Liquid base cytology improves the sensitivity of test. Liquid base cytology reduces the number of inadequate smears requiring patient call back for rescreening but is expensive.[13]

TBS (The Bethesda System) of interpretation of Pap smear is practiced by most of the centers. The squamous cellular abnormalities described in TBS are as ASC, LSIL, HSIL \& Squamous cell carcinoma.

ASC includes ASC-US - atypical cells of undermined significance which are qualitatively \& quantitatively insufficient for definite interpretation. ASC-H includes atypical cells which cannot exclude High grade squamous intraepithelial lesion. In present study ASC-H was not detected in any case.[14]

LSIL is Low grade squamous intraepithelial lesion which includes HPV related cellular changes \& CIN-I. In HPV infection, cytological changes are characterized by presence of Koilocyte with peripheral condensation of cytoplasm producing "wire-looping effect"[14].

HSIL is high grade squamous intraepithelial lesion which includes CIN-II \& CIN-III where Squamous cells with large nuclei with coarse chromatin are seen.

Important factor in accuracy of test is adequacy of specimen obtained. In our study, numbers of inadequate smears were $35(2.18 \%)$ Numbers of unsatisfactory smears were more in age group 55-70 years because of non-accessibility of Squamo-columnar junction due to estrogen deficiency.

In multicenter organized screening trial, Sankarnarayanan et al, observed $4.1 \%$ inadequate cases, while Gupta et al [15], in another study observed 7.1\% unsatisfactory samples. In our study proportion of inadequate smears was comparatively less as the smear collection was done by Gynecologist, the adequately trained health provider. The maximum numbers of women 570 out of 764 women with inflammatory changes were in age group 20-30 years. This age group being sexually active is more prone for infections.

About $10 \%$ cases of LSIL progress to HSIL within 2-4 years. Less than $50 \%$ of cases of HSIL progress to invasive carcinoma. [16] In present study, maximum numbers of cases of LSIL were detected in age group 31-35 years while in 56-60 years, eight women had LSIL. Atrophic cervicitis in postmenopausal age group may show cellular changes resembling LSIL requiring local estrogen therapy with repeat Pap smear after hormonal treatment.[17]

Maximum numbers of cases of HSIL were seen in age group 36-40 years while no HSIL detected above 65 years. As per various studies, HSIL is rare among women older than 65 years who have been previously screened. For women with negative Pap test at age of 60 years and older, the likely hood of diagnosis of HSIL on repeat screening is less than 1:1000.

Maximum numbers of cervical cancer cases (4 out of 9) were seen in age group 41-45 years. In age group 66-70 years, one woman had cancer. Detection of cancer case is believed to be due to failure of organized screening program. Such cases have been detected in earlier screening program at premalignant stage. 


\section{CONCLUSION}

Women with abnormal cervical findings on visual inspection should be subjected to Pap smear examination to detect the disease in precancerous stage so that we can initiate the treatment in most conservative form and offer better quality of life.

Visual inspection of cervix of all women and cervical cytology in high risk group having abnormal findings on visual inspection provides effective alternative approach for early detection of cervical cancer in low resource settings.

\section{ACKNOWLEDGEMENT}

We thank Dr. Acharya (Dept. of Pathology) who helped us for interpretation of Pap smear of patients.

\section{REFERENCES}

[1]. Ferlay J, Parkin DM, Pisani P. Globocan 2002 Cancer incidence, mortality and prevalence worldwide, International Agency for Research on Cancer.(IARC Cancer Base no 5, version 2.0 Lyon, France:IARC Press, 2004)

[2]. Ambika Satija Cervical Cancer In India, South Asia Centre for Chronic Disease WHO, 2009b; GLOBOCAN 2002 database, (IARC)6-26 [34]

[3]. Cervix cancer screening IARC handbooks of cancer prevention Vol.10.Lyon,France:IARC Press;2004

[4]. Hakana M .et al Evaluation of screening programs for Gynecological cancers.Br J Cancer. 1985 October; 52(4): 669-673.

[5]. International Agency for Research on Cancer (IARC) Cervix cancer screening. IARC Handbooks of Cancer Prevention, vol. 10. Lyon, France7 IARC Press; 2005.

[6]. Solomon D, Davey D, Kurman R, Moriarty A, O'Connor D, Prey M.The 2001 Bethesda System: terminology for reporting results of cervical cytology. JAMA.2002:287:2114-9.

[7]. Holowaty P ,Miller AB,Rohan T, et al. Natural history of dysplasia of the uterine cervix. Journal of the National Cancer Institute, 91(3):252

[8]. Melnikow J, Nuovo J, Willen AR, et al Natural history of cervical squamous intraepithelial lesions : A metaanalysis.Obstet.Gynecol 92 (4 pt 2):727-35,1998

[9]. Sasieni P, Castanon A, Cuzick J Effectiveness of cervical cancer screening with age : population based case control study of prospectively recorded data. $B M J 339: b 2968,2009$.

[10]. R. Sankaranarayanana, T.L.Gaffikinb, M. Jacobc, J. Sellorsd, S. Roblese A critical assessment of screening methods for cervical neoplasia.International Journal of Gynecology and Obstetrics (2005) 89, S4,S12.

[11]. Rengaswamy Sankaranarayanan, Atul Madhukar Budukh, Rajamanickam Rajkumar Effective screening programs for cervical cancer in low- and middle-income developing countries.Bulletin of the World Health Organization, 2001, (79: 954-962.)

[12]. Sankarnarayanan R, Thara S, Sharma A, Roy C, Shastri S, Mahe C et al.Accuracy of conventional cytology : results from a multicentre screening study in India. J. Med Screen.2004;11:77-84(pubmed)

[13]. Schneider V.Cervical Cancer screening, screening errors and reporting.Acta Cytol.2000;18:493-7

[14]. Bharat Rekhi, Dulhan Ajit, Santhosh K Joseph, Sonali Gswas, Kedar K Deodhar Evaluation of atypical squamous cells on conventional cytology smears. Cytojournal 2010;7:15

[15]. GuptaS, Sodhani P, Chachra KL, Singh V, Sehgal A.Outcome of squamous cells in a cervical cytology screening program: Implications for follow up in resource limited settings.DiagnCytopathol.2007;35:677-80

[16]. WHO Natural history of cervical cancer; Comprehensive cervical cancer control.A guide to essential practice by WHO Chapter 2, 37-38

[17]. Sawaya GF, Grady D, Kerlikowske K, et al.The positive predictive value of cervical smears in previously screened postmenopausal women: the Heart and Estrogen/progestin Replacement Study (HERS). Ann Intern Med 133 (12):942-50, 2000. 
Cervical cytology in women with abnormal cervix.

Table 1: Benign Cellular Changes Detected On Cervical Cytology

\begin{tabular}{|l|l|l|l|l|l|}
\hline $\begin{array}{l}\text { Age group } \\
\text { (Years) }\end{array}$ & Normal & Inflammatory & Inadequate & $\begin{array}{l}\text { Squamous } \\
\text { metaplasia }\end{array}$ & ASCUS \\
\hline $16-20$ & 10 & 25 & 0 & 1 & 0 \\
\hline $21-25$ & 46 & 335 & 0 & 42 & 0 \\
\hline $26-30$ & 35 & 235 & 0 & 59 & 3 \\
\hline $31-35$ & 113 & 63 & 0 & 7 & 5 \\
\hline $36-40$ & 134 & 67 & 2 & 5 & 3 \\
\hline $41-45$ & 98 & 8 & 3 & 2 & 4 \\
\hline $46-50$ & 32 & 15 & 1 & 0 & 2 \\
\hline $51-55$ & 28 & 8 & 3 & 1 & 0 \\
\hline $56-60$ & 3 & 5 & 5 & 0 & 3 \\
\hline $61-65$ & 3 & 3 & 9 & 0 & 0 \\
\hline $66-70$ & 0 & 0 & 7 & 0 & 0 \\
\hline $71-75$ & 0 & 0 & 5 & 0 & 0 \\
\hline Total & $\mathbf{5 0 2}$ & $\mathbf{7 6 4}$ & $\mathbf{3 5}$ & $\mathbf{1 1 7}$ & $\mathbf{2 0}$ \\
\hline
\end{tabular}

Table 2: Pre Cancerous and Cancerous Lesions Detected On Cervical Cytology

\begin{tabular}{|l|l|l|l|l|l|l|}
\hline AGE GROUP & LSIL & $95 \%$ C.I. & HSIL & 95\% C.I. & CA & $95 \%$ C.I. \\
\hline $16-20$ & 0 & - & 0 & - & 0 & - \\
\hline $21-25$ & 5 & $(-0.063,0.155)$ & 1 & $(-0.027,0.072)$ & 0 & - \\
\hline $26-30$ & 18 & $(-0.027,0.360)$ & 4 & $(-0.007,0.184)$ & 0 & - \\
\hline $31-35$ & 29 & $(0.038,0.499)$ & 10 & $(0.083,0.362)$ & 0 & - \\
\hline $36-40$ & 27 & $(0.025,0.475)$ & 14 & $(0.156,0.466)$ & 2 & $(0.160,0.285)$ \\
\hline $41-45$ & 10 & $(-0.058,0.243)$ & 6 & $(0.019,0.247)$ & 4 & $(0.370,0.519)$ \\
\hline $46-50$ & 7 & $(-0.063,0.193)$ & 5 & $(0.006,0.217)$ & 2 & $(0.160,0.285)$ \\
\hline $51-55$ & 3 & $(-0.058,0.113)$ & 2 & $(-0.025,0.114)$ & 0 & - \\
\hline $56-60$ & 8 & $(-0.062,0.210)$ & 2 & $(-0.025,0.114)$ & 0 & - \\
\hline $61-65$ & 1 & $(-0.041,0.059)$ & 1 & $(-0.027,0.072)$ & 0 & - \\
\hline $66-70$ & 0 & - & 0 & - & 1 & $(0.064,0.158)$ \\
\hline $71-75$ & 0 & - & 0 & - & 0 & - \\
\hline Total & $\mathbf{1 0 8}$ & - & $\mathbf{4 5}$ & - & $\mathbf{9}$ & - \\
\hline \% & $\mathbf{6 . 7 5 \%}$ & - & $\mathbf{2 . 8 1 \%}$ & - & $\mathbf{0 . 5 6 \%}$ & - \\
\hline
\end{tabular}

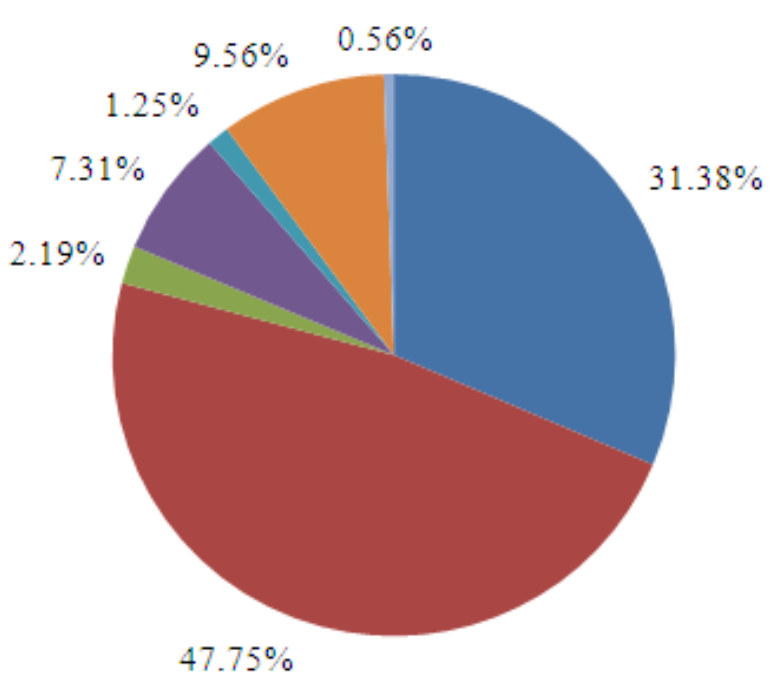

-Nomal $\mid$ Inflammatory $\mid$ Inadequate $\mid$ Squamousmetaplasia $\mid$ ASCUS $\mid$ CIN $\mid$ Cancer

Fig. 1 percentage of cellular abnormalities detected in present study 